\title{
Poly-paraphyly of Hirudinidae: many lineages of medicinal leeches
} Anna J Phillips ${ }^{* 1,2}$ and Mark E Siddall ${ }^{2}$

Address: ${ }^{1}$ Department of Biology, The Graduate Center, The City University of New York, New York, NY, USA and ${ }^{2}$ Division of Invertebrate Zoology, American Museum of Natural History, New York, NY, USA

Email: Anna J Phillips* - ajphillips@amnh.org; Mark E Siddall - siddall@amnh.org

* Corresponding author

Published: 7 October 2009

BMC Evolutionary Biology 2009, 9:246 doi:10.1/86/147/-2148-9-246

This article is available from: http://www.biomedcentral.com/I47।-2/48/9/246

(c) 2009 Phillips and Siddall; licensee BioMed Central Ltd.

This is an Open Access article distributed under the terms of the Creative Commons Attribution License (http://creativecommons.org/licenses/by/2.0), which permits unrestricted use, distribution, and reproduction in any medium, provided the original work is properly cited.

\begin{abstract}
Background: Medicinal leeches became infamous for their utility in bloodletting popularized in the 19 th century, and have seen a recent resurgence in post-operative treatments for flap and replantation surgeries, and in terms of characterization of salivary anticoagulants. Notorious throughout the world, the quintessential leech family Hirudinidae has been taken for granted to be monophyletic, as has the non-bloodfeeding family Haemopidae.
\end{abstract}

Results: This study is the first to evaluate molecular evidence from hirudinid and haemopid leeches in a manner that encompasses the global scope of their taxonomic distributions. We evaluated the presumed monophyly of the Hirudinidae and assessed previous well-accepted classification schemes. The Hirudinidae were found not to be monophyletic, falling instead into two distinct and unrelated clades. Members of the non-bloodfeeding family Haemopidae were scattered throughout the tree and among traditional hirudinid genera. A combination of nuclear I8S rDNA and 28S rDNA with mitochondrial I2S rDNA and cytochrome $c$ oxidase I were analyzed with Parsimony and with Bayesian methods.

Conclusion: The family Hirudinidae must be refined to include only the clade containing Hirudo medicinalis (European medicinal leech) and related leeches irrespective of bloodfeeding behavior. A second clade containing Macrobdella decora (North American medicinal leech) and its relatives may yet be recognized in Semiscolecidae in order to avoid paraphyly. The African distribution of species from each of the divergent hirudinid clades suggests that a deep divergence took place in the history of the medicinal leeches hundreds of millions of years ago.

\section{Background}

"Medicinal leech" is a common name that describes bloodfeeding clitellate annelids in the family Hirudinidae of the order Hirudinida. The use of leeches for bloodletting has been a part of Western medicine since Galen [1]. Indeed, the word "leech" is actually derived from the Old English word, leece, for physician (Merriam-Webster Dictionary). Their utility has also been recorded in several Eastern traditions, having been documented in the Char- aka Samhita (Maurya period, roughly 3rd century BCE) as one of five treatments for an imbalance of humors and by Wang Ch'ung (27-100 A.D) [2]. François-Joseph-Victor Broussais, physician to Napoleon and his troops, was the major proponent of leeching in Europe, particularly in the early 1800 s, during which he was infamous for using copious numbers of leeches during Napoleon's campaign through Europe [3]. As little as five and up to 50 leeches at a time were used for patients suffering from various 
conditions until Pierre Charles Alexander Louis and contemporaries finally questioned the effectiveness of phlebotomy as a cure-all; the practice was not curbed until approximately 100 years later $[4,5]$.

As a result of their great medical popularity during the $18^{\text {th }}$ and $19^{\text {th }}$ centuries, European leech populations were over-harvested and leeches became increasingly scarce in parts of Western Europe. Consequently, various countries, such as Italy, Hungary, and Poland, with seemingly abundant sources, began exporting large numbers in order to satisfy the high demand. As early as 1823 , restrictions were put in place to manage the number of leeches being exported through Hannover, Germany, and collecting seasons were instituted in Russia; these represent some of the first measures in history meant to conserve an animal species [6].

The clinical use of leeches was revived by Derganc and Zdravic [7] to relieve post-operative venous congestion in patients recovering from tissue flap and replantation surgery. Their application in this regard proved so successful that European medicinal leeches were approved by the US Food and Drug Administration in June, 2004 as a medical device due to their mechanically relieving venous congestion and delivering anti-coagulants [8]. The powerful anticoagulants in leech salivary secretions have been of interest since the anti-thrombin, hirudin, was purified [9]. The first human dialysis treatment accomplished by Haas [10] was only possible in light of the newly available purified hirudin, though it would later be supplanted by widely available and less expensive heparin.

The namesake of the family Hirudinidae, Hirudo medicinalis Linnaeus, 1758 (European Medicinal Leech), is the species most commonly referenced for its use in medicine, though a recent study $[11,12]$ found the commercially distributed leech used in most Western hospitals is Hirudo verbana Carena 1820, not $H$. medicinalis. In fact, within the family Hirudinidae, approximately 200 species have been described from all continents, save for Antarctica. Some of these species are used in medical practices in place of Hirudo species where they are abundant (e.g., Richardsonianus australis (Bosisto, 1859), Hirudinaria manillensis (Lesson, 1842), and Hirudo nipponia Whitman 1886 [13]).

Traditionally, the family Hirudinidae included any sanguivorous, swimming, freshwater leech with three jaws (one dorsal and two ventrolateral) and a distinctively caecate crop. Richardson [14] separated the Hirudinidae into five families, which Sawyer [15] made into new combinations and subfamilies of the family Hirudinidae based on sexual morphology and geographic distributions (Figure 1). Apakupakul et al. [16] suggested that the Hirudinidae is polyphyletic, finding the North American medicinal

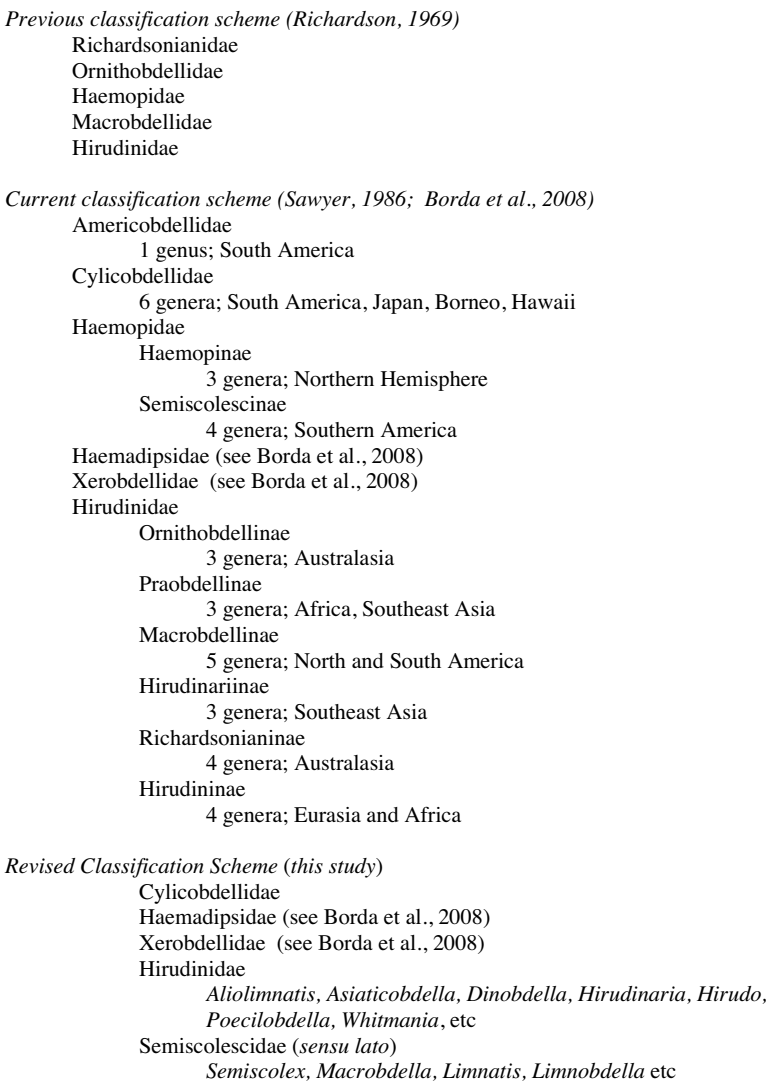

Figure I

Classification schemes of the suborder Hirudiniformes.

leech Macrobdella decora (Say, 1824) to be only distantly related to $H$. medicinalis. Borda and Siddall's [17] analyses found the family Hirudinidae to be split into two major clades with the terrestrial leeches and the non-bloodfeeding Haemopidae falling in between. All taxonomic revisions of the family until now have been performed only with morphological characters [e.g., $[14,15,18]]$. Here, we revisit the phylogenetic relationships and systematics of the family Hirudinidae while testing the monophyly of the family, and for the first time utilizing an expanded taxon sampling from each continent with representatives of most previously proposed subfamilies.

\section{Results}

The combined dataset had a total of 6086 characters (18S: 2034 characters, 28S: 2162 characters, 12S: 575 characters, CO1: 1315 characters). The Parsimony analysis produced 9 equally parsimonious trees with 8266 steps while the harmonic mean of log-likelihood values from two runs of the Bayesian (BI) analysis averaged -44555.69 . The log-likelihood of the topology produced by the Maximum Likelihood analysis was -43311.984. 


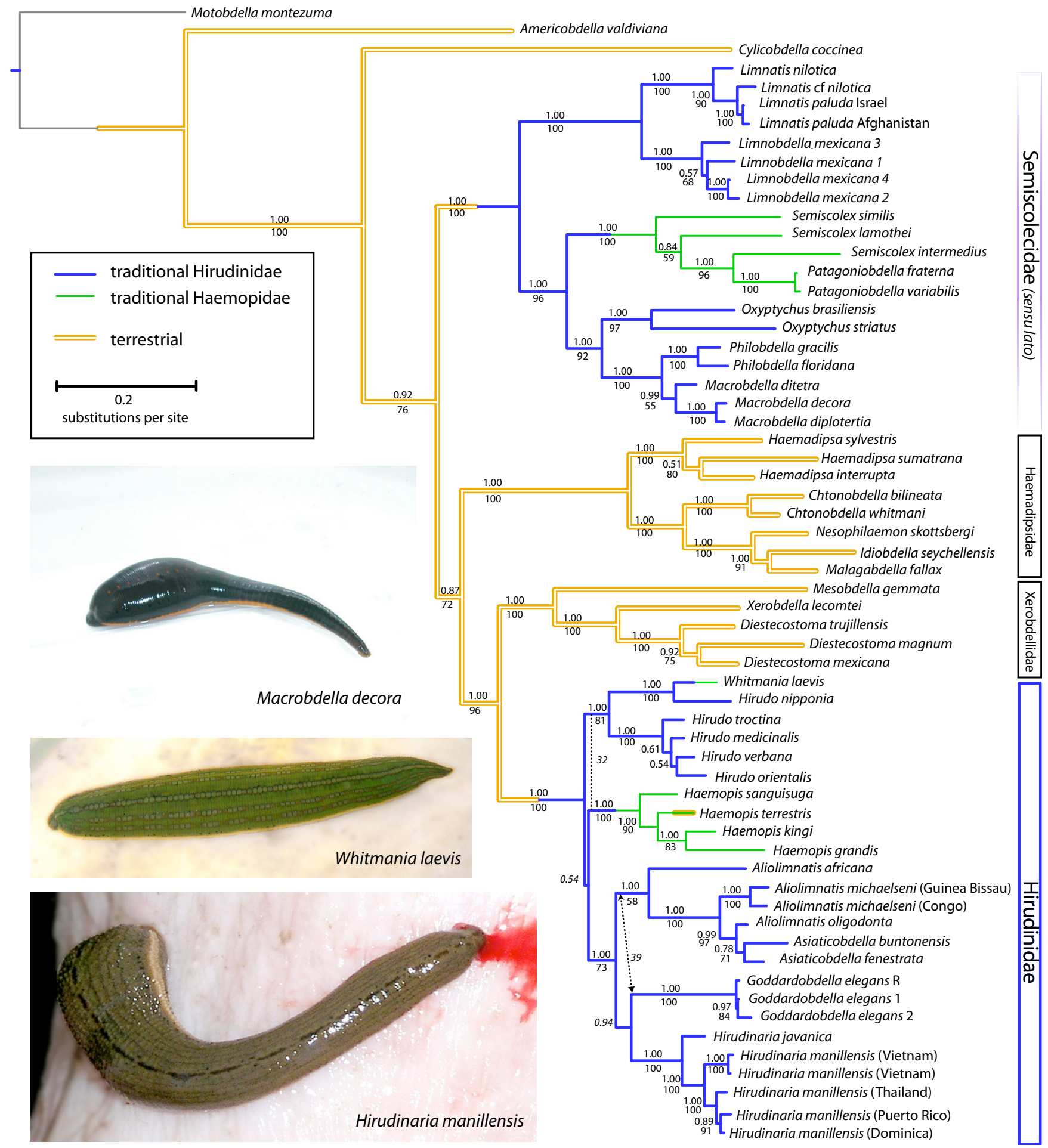

Figure 2

Maximum Parsimony and Bayesian Inference tree topology based on I8S rDNA, 28S rDNA, I2S rDNA, and COI datasets combined. Posterior probabilities are above the node and jackknife values are below the node. Branch lengths in orange corresponds to terrestrialism, branch lengths in blue correspond to traditional members of the family Hirudinidae, and branch lengths in green correspond to traditional members of the family Haemopidae. 
Parsimony and BI methods largely agreed in terms of the tree topology, including that the family Hirudinidae was not monophyletic (Figure 2). In parsimony, monophyly of an a priori presumed-monophyletic Hirudinidae would require 179 extra steps (Templeton test: $z=-8.299, P>$ $0.0001)$. The harmonic mean of log-likelihood values constraining traditional hirudinids to be monophyletic was -45054.72 (yielding a Bayes Factor of -998.06). Similarly, with this constraint under the likelihood criterion, monophyly of Hirudinidae was rejected with Treefinder [19], in that $P$-values were highly significant (ShimodiaraHasegawa < 0.000001, approximately unbiased test < $0.000001)$. The harmonic mean of log-likelihood values constraining traditional hirudinids and traditional haemopids together to be a monophyletic group was 44589.01 (yielding a Bayes Factor of -66.64). Similarly, with this constraint under the likelihood criterion, monophyly of Hirudinidae+Haemopidae was rejected with Treefinder [19], in that $P$-values, while not as profound as in the simple case of constraining Hirudinidae to be monophyletic, still were significant at the $5 \%$ level (Shimodiara-Hasegawa $=0.0195$, approximately unbiased test $=0.0164)$.

Hirudinid taxa placed among two strongly supported clades (Figure 2). One clade contained the genera Macrobdella, Philobdella, Oxyptychus, Semiscolex, Patagoniobdella, Limnobdella, and Limnatis. A second clade contained the genera Aliolimnatis, Asiaticobdella, Hirudinaria, Goddardobdella, Hirudo, Whitmania, and Haemopis. The precise placement of the genus Haemopis varied among analyses and received little support in each of Parsimony (jackknife = $32)$ and $\mathrm{BI}(\mathrm{pp}=0.54)$ analyses. Between the two principal hirudinid clades was a paraphyletic assemblage of terrestrial leeches in the families Haemadipsidae and Xerobdellidae. The Parsimony analysis found the genus Haemopis to be sister to the Hirudo clade (including Whitmania laevis (Baird, 1869)), whereas the BI analyses found the genus Haemopis sister to a clade comprised of the genera Aliolimnatis, Asiaticobdella, Goddardobdella, and Hirudinaria, exclusive of the genus Hirudo. Species-level disagreements were apparent between the Parsimony analysis and the BI analyses involving species of Hirudo as well as species of Aliolimnatis and Asiaticobdella. Regardless of optimality criterion, within the Hirudo clade were the various European Hirudo species along with the Asian $H$. nipponia, which itself was sister to the Asian non-sanguivorous $W$. laevis (traditionally Haemopidae). Within its own clade, H. manillensis individuals were clustered by locality with Caribbean individuals closely related to those from Thailand. Representatives of the genus Asiaticobdella fell within, and rendered paraphyletic, the genus Aliolimnatis. Regardless of optimality criterion, the genera Macrobdella, Philobdella, and Oxyptychus each were monophyletic and together formed a clade that was sister to the non-sanguivorous Semiscolescidae (also traditionally Haemopidae) as opposed to the bloodfeeding genera, Limnatis and Limnobdella. Mexican leeches of the genus Limnobdella formed a monophyletic group sister to the monophyletic genus Limnatis with high support values (jackknife = 100; pp = 1.00).

\section{Discussion}

The family Hirudinidae, long taken for granted to be monophyletic, is not. Hirudinid leeches, characterized as relatively large, vermiform, swimming leeches that feed on blood by making an incision with three armed jaws, fall into two separate clades: one typified by the North American M. decora and the other by the European $H$. medicinalis. The Hirudinidae is represented by two independent origins of aquatic medicinal leeches, each from a terrestrial ancestor. Both groups create spongy cocoons that are deposited on shore, leaving the hatchlings to search for the water in a manner similar to newly hatched sea turtles. Also, both groups have internal insemination, a behavior common to terrestrial organisms to prevent sperm desiccation, unlike the aquatic leech families Glossiphoniidae and Piscicolidae that exhibit external traumatic insemination. The clade containing $M$. decora includes additional New World genera, such as the South American Oxyptychus, Semiscolex, and Patagoniobdella, as well as the North American Macrobdella, Philobdella, and Limnobdella. Unexpectedly, within this otherwise New World clade is the Old World bloodfeeding genus Limnatis distributed from Eastern Europe, throughout Africa, and eastward to the Indian subcontinent. The second hirudinid clade contains $H$. medicinalis and related genera found only in the Old World including Africa (Aliolimnatis and Asiaticobdella spp.), Asia (Hirudinaria spp., some Hirudo spp., and Whitmania spp.), Australia (Goddardobdella spp.), and Europe (Hirudo spp.). This polyphyly of the family Hirudinidae is further complicated by each of the two clades' inclusion of non-bloodfeeding taxa heretofore assigned to the family Haemopidae [15].

The deep divergence between the two hirudinid clades was hinted at by Borda and Siddall [17] in their findings that the Old World Limnatis nilotica (Savigny, 1822) placed closer to the North American M. decora than to other African species of the genus Aliolimnatis. With our addition of members of the genus Limnobdella that group sister to Limnatis species, the nature of this relationship is more precise. Prior work regarding the anticoagulant profiles of various medicinal leeches may have been prescient regarding polyphyly of the so-called "medicinal leeches". A variety of anticoagulants have been characterized from hirudinid leeches, with each compound targeting a different point in the clotting process $[20,21]$. It is generally held that the major protease inhibitors employed by Hirudo species and their allies block thrombin, whereas 
that for M. decora targets platelet aggregation as opposed to the clotting cascade itself [e.g., [22,23]]. Regarding the close association of Old World Limnatis species and New World Limnobdella species, generalized morphological similarities have previously been noted. Richardson and Oosthuizen lamented in personal letters (in the possession of MES) their inability to find a synapomorphy for the two genera that might allow them to erect a new family.

As noted above, in addition to the polyphyletic origin of the medicinal leeches, both hirudinid clades are paraphyletic in light of members of the family Haemopidae placing within each group. Previously, non-bloodfeeding, relatively large, vermiform, swimming leeches were grouped together on the basis of their macrophagous feeding behavior, regardless of geographic distribution. The family Haemopidae, among other non-bloodfeeding taxa, included the genera Haemopis, Whitmania, Semiscolex, and Patagoniobdella [15]. Our analyses demonstrate that this family is not phylogenetically corroborated because haemopid genera fall variously within the two independent hirudinid clades, thus rendering them paraphyletic. Whitmania laevis is sister to a bloodfeeding species within the genus Hirudo, and not even monophyletic with the other nearby non-bloodfeeding species of Haemopis. The macrophagous genera Semiscolex and Patagoniobdella, while monophyletic, are sister to a clade containing the sanguivorous taxa, Oxyptychus, Macrobdella and Philobdella. Though the ancestral hirudinid was clearly a bloodfeeder [17], what is remarkable is the number of times that sanguivory has been abandoned by this group of annelids otherwise notorious for its ectoparasitic dependence on vertebrate blood. Already the loss of sanguivory has been inferred for other groups of leeches such as Erpobdellidae, with a predilection for chironomid larvae, and the glossiphoniid genera Helobdella, Glossiphonia, and Alboglossiphonia that prefer the hemolymph of gastropods or other annelids. Even the terrestrial haemadipsid, Idiobdella seychellensis Harding, 1913 shifted away from feeding on blood on remote islands where terrestrial gastropods are more plentiful (and often larger) than resident anurans [24].

To reflect the phylogeny, the family Hirudinidae sensu stricto must hereafter exclude those bloodfeeding taxa unrelated to $H$. medicinalis and minimally includes those more closely related sanguivores [e.g., Hirudo, Goddardobdella, Hirudinaria, Aliolimnatis, Asiaticobdella included here], but must also include the non-sanguivorous genera Haemopis and Whitmania if leech taxonomy is to avoid both polyphyly and paraphyly of this family. The remaining genera previously included in the family Hirudinidae are in want of a unifying taxonomic name. Macrobdellidae [14] could include the genera Macrobdella, Philobdella, and Oxyptychus so as to reflexively retain a family for the non-bloodfeeding Semiscolescidae (Sciban \& Autrum, 1934), their sister taxon. Yet, this would leave the genera Limnatis and Limnobdella without a synapomorphy for any family that would be required to include them. Conveniently, the Hirudinidae sensu stricto are easily differentiated from the hirudinid clade typified by $M$. decora by virtue of their profoundly muscular ejaculatory bulbs in the median male reproductive apparatus that are efferent to the epididymes; a characteristic Hirudinidae shares with the Haemadipsidae. In the absence of a clear morphological synapomorphy for the Limnobdella/Limnatis clade, we acknowedge that the genera Macrobdella, Philobdella, Oxyptychus, Limnobdella, Limnatis, and Semiscolex could presently be considered genera in the family Semiscolescidae (sensu lato), in that this family has taxonomic priority over the alternatives. Ironically, such a revision would leave the characteristically bloodfeeding Hirudinidae encompassing some non-bloodfeeding taxa and the traditionally non-bloodfeeding family Semiscolescidae (sensu lato) including notable bloodfeeders.

The genus Patagoniobdella is, by virtue of its relationships, merely a junior synonym of Semiscolex. Asiaticobdella fenestrata (Moore, 1939) falls within the genus Aliolimnatis. It is likely that these two genera will have to be synonymized, though we are presently reluctant in the absence of either of the type species for the genera. Similarly, though W. laevis falls within the genus Hirudo, formal revision should require the inclusion of the type species, Whitmania pigra (Whitman, 1884).

Both H. nipponia and L. nilotica are known to include multiple morphological variants [25] (Oosthuizen notes in the possession of MES) over a wide distribution (the latter from Eastern Europe through the entire continent of Africa and parts of India, and the former throughout much of East Asia) and so most likely these each represent multiple lineages. Notably, our determinations of the identity of leeches matching the description of L. nilotica represent a paraphyletic assemblage relative to $L$. paluda. More sampling across the range of these taxa is needed in order to better define lineages and distinguish potentially cryptic species.

While there are no fossil data for correlation in historical interpretations of the Hirudinidae, geologic events can be used as a rough estimate when considering the current distributions of leech taxa. Assuming a vicariance-dominated explanation, both clades would have had to originate on Pangea with significant diversification in all groups prior to the supercontinent's breakup. The Semiscolecidaerelated group seems to have originated in South America with diversification into the clades containing Oxyptychus, Semiscolex, and Patagoniobdella on that continent before 
Table I: Taxa used for the phylogenetic analyses of the family Hirudinidae along with collection localities and GenBank accession numbers

\begin{tabular}{|c|c|c|c|c|c|}
\hline \multirow[t]{2}{*}{ Taxon } & \multirow[t]{2}{*}{ Locality } & \multicolumn{4}{|c|}{ GenBank Accession Numbers } \\
\hline & & $18 S$ & $28 S$ & $12 S$ & COI \\
\hline \multicolumn{6}{|l|}{ Ingroup } \\
\hline Aliolimnatis africana & Ctr. African Rep. & AY425469 & AY425387 & $\underline{\text { AY425428 }}$ & AY42545I \\
\hline Aliolimnatis michaelseni & Guinea Bissau & GQ368780 & GQ36876I & GQ368803 & GQ368738 \\
\hline Aliolimnatis michaelseni & Congo & $\underline{\mathrm{AFI}} 16010$ & AY425388 & AY425429 & $\underline{\mathrm{AF} I 16029}$ \\
\hline Aliolimnatis oligodonta & Tanzania & $\underline{\text { GO368781 }}$ & GQ368762 & $\longrightarrow$ & GQ368739 \\
\hline Aliolimnatis buntonensis & South Africa & GQ368782 & - & - & $\underline{\text { GQ368740 }}$ \\
\hline Asiaticobdella fenestrata & Zambia & $\underline{\text { GQ368783 }}$ & $\underline{\text { GQ368763 }}$ & GQ368804 & GQ36874I \\
\hline Chtonobdella bilineata & Australia & $\underline{\mathrm{AFI}} 16006$ & $\underline{A Y 425361}$ & $\longrightarrow$ & AF003267 \\
\hline Chtonobdella whitmani & Australia & EUI00065 & EUI00074 & - & EUI00087 \\
\hline Diestecostoma magnum & Mexico & EUI00067 & EU100076 & 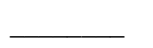 & EU100088 \\
\hline Diestecostoma mexicana & Mexico & EUI00068 & EUI00077 & $\longrightarrow$ & EUI00089 \\
\hline Diestecostoma trujillensis & Mexico & EU100066 & EUI00075 & $\longrightarrow$ & EU100090 \\
\hline Goddardobdella elegans I* & Australia & $\underline{\mathrm{GO} 368784}$ & $\underline{\text { GO368764 }}$ & $\underline{\mathrm{GO} 368805}$ & $\underline{\mathrm{GO} 368742}$ \\
\hline Goddardobdella elegans $2 *$ & Australia & GQ368785 & GQ368765 & GQ368806 & GQ368743 \\
\hline Goddardobdella elegans $\mathrm{R}^{*}$ & Australia & GQ368786 & GQ368766 & GQ368807 & GQ368744 \\
\hline Haemadipsa interrupta & Thailand & EU100069 & EUI00078 & $\longrightarrow$ & EUI00091 \\
\hline Haemadipsa sylvestris & Vietnam & $\underline{\mathrm{AFI} I 6005}$ & $\underline{\mathrm{AY} 425373}$ & AY425416 & AF003266 \\
\hline Haemadipsa sumatrana & Borneo & $\underline{\text { AY425464 }}$ & AY425372 & $\underline{A Y 425415}$ & AY425446 \\
\hline Haemopis grandis & Manitoba & $\underline{A Y 425465}$ & AY425377 & AY425420 & AY425447 \\
\hline Haemopis kingi & Manitoba & AY425466 & AY425378 & AY425421 & AY425448 \\
\hline
\end{tabular}


Table I: Taxa used for the phylogenetic analyses of the family Hirudinidae along with collection localities and GenBank accession numbers (Continued)

\begin{tabular}{|c|c|c|c|c|c|}
\hline Haemopis sanguisuga* & Sweden & AF09994I & AY425381 & $\underline{\text { AF099960 }}$ & AF462021 \\
\hline Haemopis terrestris & $\mathrm{OH}$, USA & AY786465 & EUI00080 & $\longrightarrow$ & EUI00092 \\
\hline Hirudinaria javanica* & Vietnam & $\underline{\text { GQ368787 }}$ & $\underline{\text { GQ368767 }}$ & $\underline{\text { GQ368808 }}$ & $\underline{\text { GQ368745 }}$ \\
\hline Hirudinaria manillensis & Dominican Rep. & GQ368788 & $\underline{\text { GQ368768 }}$ & $\underline{\text { GQ368809 }}$ & $\longrightarrow$ \\
\hline Hirudinaria manillensis & Puerto Rico & AY425467 & AY425384 & AY425426 & AY425449 \\
\hline Hirudinaria manillensis & Thailand & GQ368789 & $\underline{\text { GQ368769 }}$ & - & GQ368746 \\
\hline Hirudinaria manillensis II & Vietnam & GQ368791 & $\underline{\text { GQ36877I }}$ & $\underline{\text { GU04556I }}$ & $\underline{\mathrm{GQ} 368748}$ \\
\hline Hirudinaria manillensis 24 & Vietnam & GQ368790 & GQ368770 & GQ368810 & GQ368747 \\
\hline Hirudo medicinalis* & BioPharm, UK & $\underline{A F I I 60 I I}$ & AY425385 & AF099961 & $\underline{\text { AF003272 }}$ \\
\hline Hirudo nipponia & Korea & $\underline{\text { AY425468 }}$ & $\underline{\text { AY425386 }}$ & $\underline{\text { AY425427 }}$ & $\underline{\text { GQ368749 }}$ \\
\hline Hirudo orientalis & Azerbaijan & GQ368792 & $\longrightarrow$ & $\underline{\text { GQ3688II }}$ & $\underline{\text { GQ368750 }}$ \\
\hline Hirudo troctina & Morocco & GQ368793 & GQ368772 & GQ3688I2 & GQ36875I \\
\hline Hirudo verbana & Leeches USA & GQ368794 & $\underline{\text { GQ368773 }}$ & $\underline{G Q 368813}$ & GQ368752 \\
\hline Idiobdella seychellensis & Seychelles & EUI00070 & EUI0008I & - & EUI00094 \\
\hline Limnatis nilotica* & Bosnia & $\longrightarrow$ & $\longrightarrow$ & AY763161 & AY763152 \\
\hline Limnatis cf. nilotica & Namibia & GQ368795 & $\underline{\text { GQ368774 }}$ & $\underline{\text { GQ3688I5 }}$ & GQ368754 \\
\hline Limnatis paluda & Afghanistan & GQ368796 & GQ368775 & 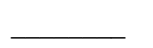 & GQ368755 \\
\hline Limnatis paluda & Israel & AY425470 & AY425389 & AY425430 & AY425452 \\
\hline Limnobdella mexicana I* & Mexico & GQ368797 & GQ368776 & $\underline{G Q 368818}$ & GQ368758 \\
\hline Limnobdella mexicana $2 *$ & Mexico & $\longrightarrow$ & $\longrightarrow$ & $\underline{G Q 368819}$ & GQ368759 \\
\hline Limnobdella mexicana 3* & Mexico & GQ368798 & GQ368777 & GQ368816 & GQ368756 \\
\hline Limnobdella mexicana $4 *$ & Mexico & $\underline{\text { GQ368799 }}$ & $\underline{\mathrm{GQ} 368778}$ & $\underline{\mathrm{GQ} 368817}$ & $\underline{\text { GQ368757 }}$ \\
\hline Macobdella decora* & MI, USA & $\underline{\mathrm{AFI}} 16007$ & AY425390 & AY425431 & AF00327I \\
\hline
\end{tabular}


Table I: Taxa used for the phylogenetic analyses of the family Hirudinidae along with collection localities and GenBank accession numbers (Continued)

\begin{tabular}{|c|c|c|c|c|c|}
\hline Macrobdella diplotertia & MO, USA & DQ097214 & DQ097205 & + & DQ097223 \\
\hline Macrobdella ditetra & GA, USA & AY42547I & AY425391 & AY425432 & AY425453 \\
\hline Malagadbdella fallax & Madagascar & EUI0007I & EUI00083 & 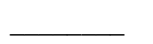 & EU100096 \\
\hline Mesobdella gemmata & Chile & AY425472 & EUI00084 & 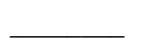 & EUI00097 \\
\hline Nesophilaemon skottsbergi & Juan Fernandez Island & EUI00072 & EUI00085 & $\longrightarrow$ & EU100098 \\
\hline Oxyptychus brasiliensis & Brazil & AY425473 & AY425398 & AY425436 & AY425455 \\
\hline Oxyptychus striatus* & Argentina & AY425474 & AY425399 & $\longrightarrow$ & $\longrightarrow$ \\
\hline Patagoniobdella fraterna & Chile & AY425477 & AY425405 & AY42544I & AY425459 \\
\hline Patagoniobdella variabilis* & Chile & AY425476 & 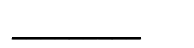 & 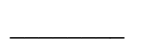 & AY425458 \\
\hline Philobdella floridana* & SC, USA & DQ097210-13 & DQ09720I-14 & DQ097226 & DQ097219-22 \\
\hline Philobdella gracilis & LA, USA & DQ097209 & DQ097200 & DQ097225 & DQ097218 \\
\hline Semiscolex intermedius & Argentina & GQ368800 & $\longrightarrow$ & $\longrightarrow$ & GU045562 \\
\hline Semiscolex lamothei & Mexico & GQ36880I & $\longrightarrow$ & $\longrightarrow$ & GU045563 \\
\hline Semiscolex similis & Bolivia & AY425475 & AY425402 & AY42543 & AY425475 \\
\hline Whitmania laevis & Taiwan & AY786467 & AY786454 & AY786447 & 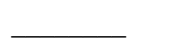 \\
\hline Xerobdella lecomtei & Slovenia & AF099947 & EU100086 & $\overline{-}$ & EU100099 \\
\hline
\end{tabular}

Outgroup

\begin{tabular}{|c|c|c|c|c|c|}
\hline Americobdella valdiviana & Chile & AY42546I & AY425358 & AY425407 & AY425443 \\
\hline Cylicobdella coccinea & Bolivia & $\underline{A Y 425462}$ & AY425362 & AY4254II & AY425444 \\
\hline Erpobdella montezuma & AZ, USA & GQ368802 & GQ368779 & GQ368820 & GQ368760 \\
\hline
\end{tabular}

* indicates type species for the genera of the Ingroup 
approximately three Mya when North and South America became proximal. Thereafter, the lineage leading to Macrobdella and Philobdella could have dispersed north, a pattern mirrored in other leech groups, such as Helobdella and Haementeria [26]. Some diversification would have had to occur prior to the breakup of Pangea in order to explain the presence of the genus Limnobdella in the New World and the genus Limnatis in Old World locales. Long distance dispersal of some ancestral Limnatis or Limnobdella species should be considered, though presently this is only known for terrestrial leeches in the family Haemadipsidae feeding on birds.

The clade containing $H$. medicinalis also seems to have undergone an intense period of diversification around the time of the breakup of Pangea. The node joining the Aliolimnatis/Asiaticobdella, Hirudinaria, and Goddardobdella clades is short and unstable suggesting a rapid diversification associated with the continental breakup of Pangea during the Cretaceous. Closely related taxa from Africa, Australia, and Southeast Asia follow a Gondwanan vicariance distribution, distinctly separate from the Laurasian Haemopis/Hirudo sector of the Hirudinidae sensu stricto. The sister group relationship of $H$. nipponia and $W$. laevis reflects the geologic history of Asia with their northerly origin in Laurasia and a later dispersal of the non-bloodfeeder into southern regions following a period of isolation from the remaining Hirudinidae by the presence of the Turgai Sea (93 - 89 Mya) [27]. The unusual recent distribution of $H$. manillensis in the Caribbean closely related to the others from (for example) Thailand can only be explained by $H$. manillensis having been introduced to the Caribbean in the 1800s by physicians using leeches on board galleons transporting goods and persons between Spanish holdings in the Pacific and the New World $[28,29]$. Clarity regarding this potentially invasive species might be better assessed through haplotype analyses involving individuals from the Philippines and Northern Taiwan, which were under Spanish influence when leech phlebotomy was heavily practiced by European surgeons.

Despite extensive collection efforts, the type species of several genera in the family Hirudinidae have not been included in this analysis. These include Aliolimnatis diversa Richardson, 1972, Asiaticobdella birmanica (Blanchard, 1894), Semiscolex juvenilis Kinberg, 1866, and Whitmania pigra (Whitman, 1884). As such, definitive segregation of genera, and even their proper familial designations remain underdetermined. Approximately 15 genera, an inordinate numberof which are monotypic taxa from Australia described by Richardson [14], are not yet included in phylogenetic analyses. We anticipate that the addition of these and the multitudinous, however poorly distinguished, species described by Sciacchitano from Africa [e.g., [30-32]], might yet provide better support for some nodes, and further our understanding of the interrelationships of these medically important annelids.

\section{Conclusion}

The finding that the two groups of medicinal leeches have independent evolutionary origins is not surprising because the two clades do have subtle morphological and behavioral differences. Hirudo species when swimming form a complete sine wave with their bodies, while $M$. decora forms a sine wave and a half. Also, different anticoagulants are produced by each group [21]. This division, now supported by molecular data, calls for an extensive revision of all hirudinid-like taxa. Each taxon will have to be carefully evaluated as some are not placing as would be expected; a prime example being members of the genus Limnatis. This brings a large majority of leech systematics into question, and has far reaching implications. The distinctions are critical to researchers who use members of the Hirudinidae in their work, such as neurobiologists who use $H$. medicinalis as a model organism. These findings will have a greater impact upon those interested in characterizing the anticoagulants isolated from the members of the two clades, making knowledge of the proper evolutionary history of the group essential to giving context to future results.

\section{Methods \\ Taxon selection}

A total of 48 species composing 61 terminal taxa were used in the analyses (Table 1). Taxa new to phylogenetic analyses include: Motobdella montezuma Davies, 1985, Limnobdella mexicana Blanchard, 1893 from several localities, Limnatis cf. nilotica, Limnatis paluda (Tennent, 1859), Semiscolex intermedius Ringuelet, 1942, Semiscolex lamothei Oceguera-Figueroa, 2005, Asiaticobdella fenestrata (Moore, 1939), and Goddardobdella elegans (Grube, 1867). Species involved in previous analyses, but in this study with new material, include: Aliolimnatis michaelseni (Augener, 1936), Haemopis sanguisuga (Linnaeus, 1758), Hirudinaria javanica (Wahlberg, 1856), Hirudinaria manillensis (Lesson, 1842) from several localities, Hirudo troctina Johnson, 1816, and Whitmania laevis (Baird, 1869).

Three arhynchobdellid outgroup taxa were included in the analyses: Americobdella valdiviana (Philippi, 1872) of the family Americobdellidae, Cylicobdella coccinea Kennel, 1886 of the family Cylicobdellidae, and Motobdella montezuma of the family Erpobdellidae. An additional 17 hirudiniform taxa from the families Haemadipsidae and Xerobdellidae were used for comparative purposes. The three outgroup taxa were selected based on prior phylogenetic work [16]. Locality data and GenBank Accession Numbers are listed in Table 1. 
Specimens were identified using morphological characters. These included examination of arrangement of eyespots, number of annuli separating the gonopores, number of gastic caecae, and the size and shape of internal reproductive organs such as the penis, vagina, testisacs, ovaries, and common oviduct if present. During this process, it was determined that a specimen used in earlier studies previously identified as L. nilotica (18S: AY425470, 28S: AY425389, 12S: AY425430, CO1: AY425452) collected in Israel used in Borda and Siddall [17] was actually L. paluda. The morphological differences between the two species was verified by the examination of the morphology of the L. paluda specimen from Afghanistan.

\section{DNA extraction and purification}

Specimens were stored at either $-20^{\circ} \mathrm{C}$ or at ambient temperature in $95-100 \%$ ethanol. Tissue was collected from the caudal sucker rather than from gastric or intestinal regions to avoid contamination of the host/prey DNA. A DNeasy Tissue Kit (Qiagen Valencia, CA) was used for tissue lysis and DNA purification.

\section{DNA amplification}

Primers used in Borda and Siddall [17] were used for the PCR amplification of nuclear 18S rDNA (18S) and 28S rDNA (28S) and mitochondrial 12S rDNA (12S) gene fragments. PCR amplification of mitochondrial cytochrome $c$ oxidase I (COI) gene fragments was accomplished using the primers COI-A and COI-B [33] or LCO1490 and HCO2198 [17]. All amplification reactions of gene fragments were made using Ready-To-Go PCR Beads (Amersham Pharmacia Biotech, Piscataway, NJ) with $0.5 \mu \mathrm{l}$ of each $10 \mu \mathrm{M}$ primer, $1 \mu \mathrm{l}$ DNA template, and $23 \mu \mathrm{l}$ RNase-free $\mathrm{H} 2 \mathrm{O}$ (total volume $25 \mu \mathrm{l}$ ) and were performed in an Eppendorf $\mathrm{f}^{\circledast}$ astercycler ${ }^{\circledast}$. The following amplification protocols were used: for $18 \mathrm{~S}, 94^{\circ} \mathrm{C}$ for 1 min, followed by 35 cycles of $94^{\circ} \mathrm{C}(30 \mathrm{sec}), 49^{\circ} \mathrm{C}(30$ $\mathrm{sec}), 68^{\circ} \mathrm{C}(2 \mathrm{~min} 30 \mathrm{sec})$ and a final extension at $68^{\circ} \mathrm{C}$ for 1 minute; for $28 \mathrm{~S}$ and $12 \mathrm{~S}, 94^{\circ} \mathrm{C}$ for $5 \mathrm{~min}$, followed by 39 cycles of $95^{\circ} \mathrm{C}(1 \mathrm{~min}), 52^{\circ} \mathrm{C}(1 \mathrm{~min}), 70^{\circ} \mathrm{C}(1$ $\mathrm{min}$ ) and a final extension of $72^{\circ}$ for 7 minutes; for COI, $94^{\circ} \mathrm{C}$ for $1 \mathrm{~min}$, followed by 30 cycles of $94^{\circ} \mathrm{C}(30 \mathrm{sec})$, $48^{\circ} \mathrm{C}(30 \mathrm{sec}), 68^{\circ} \mathrm{C}(45 \mathrm{sec}), 68^{\circ} \mathrm{C}(1 \mathrm{~min})$ and a final extension of $68^{\circ} \mathrm{C}$ for $1 \mathrm{~min}$. PCR amplification products were purified with AMPure ${ }^{\mathrm{TM}}$ (Agencourt Bioscience Corporation).

\section{DNA sequencing and alignment}

Cycle sequence reactions were performed with an Eppendorf Mastercycler ${ }^{\circledast}$ using one of two different strategies: 7 $\mu \mathrm{l}$ Rnase-free $\mathrm{H}_{2} \mathrm{O}, 1 \mu \mathrm{l}$ ABI Big Dye ${ }^{\mathrm{TM}}$ Terminator (v1.1 or v3.1), $1 \mu \mathrm{l} \mathrm{Big} \mathrm{Dye}{ }^{\mathrm{TM}}$ Extender Buffer (v1.1 or v3.1), $1 \mu \mathrm{l}$ of $1 \mu \mathrm{M}$ primer and $3 \mu \mathrm{l}$ of cleaned PCR template $(13 \mu \mathrm{l}$ total volume) or $0.5 \mu \mathrm{l} \mathrm{ABI} \mathrm{Big} \mathrm{Dye}{ }^{\mathrm{Tm}}$ Terminator (v1.1 or v3.1), $0.5 \mu \mathrm{l} \mathrm{Big}$ Dye $^{\mathrm{ru}}$ Extender Buffer (v1.1 or v3.1), $1 \mu \mathrm{l}$ of 1 $\mu \mathrm{M}$ primer and $3 \mu \mathrm{l}$ of cleaned PCR template ( $5 \mu \mathrm{l}$ total volume). Sequences were purified by $70 \%$ isopropanol/ $70 \%$ ethanol precipitation and analyzed with an ABI PRISM $^{\circledast} 3730$ sequencer (Applied Biosystems). CodonCode Aligner (CodonCode Corporation) was used to edit and reconcile sequences. Alignments of all genes were accomplished using the European Bioinformatics Institute server for MUSCLE applying default settings (MUltiple Sequence Comparison by Log-Expectation) v. 3.7 [34].

\section{Phylogenetic analyses}

Parsimony analyses of the genes (18S, 28S, COI, and 12S) in combination were performed using PAUP* [4.02b] [35]. Heuristic searches used 500 replicates of random taxon addition and tree-bisection-reconnection branch swapping. All characters were left unweighted and nonadditive. Gaps were treated as missing data. Parsimony jackknife values for combined analyses were obtained using random taxon addition and tree-bisection-reconnection branch swapping with $36 \%$ deletion and 100 heuristic pseudoreplicates [36].

Bayesian Inference was performed on the combined dataset using MrBayes v. 3.1.2 [37]. The data were partitioned by gene for $18 \mathrm{~S}, 28 \mathrm{~S}, 12 \mathrm{~S}$, and by codon position for COI (three partition; $3 p$ ). A GTR $+\Gamma+\mathrm{I}$ model was assumed for each unlinked data partition based on the AIC (via ModelTest v. 3.7) [38,39]. For the Metropolis-Coupled Markov Chain Monte Carlo (MCMCMC) analyses, default prior distributions of parameters were used twice with one cold chain and three hot chains for 10 million generations and sampled every $1000^{\text {th }}$ generation. The BI analyses burnedin before 2,600,000 generations. Split frequencies of the standard deviation of simultaneous BI analyses were well below 0.01 . As such, the burn-in was set to discard the first three million generations, leaving 7,000 trees sampled for estimation of posterior probabilities (pp).

Maximum Likelihood analyses were performed on the combined dataset using Treefinder [19] with the GTR $+\Gamma$ $+\mathrm{I}$ model applied for each unlinked data partition with default settings.

Monophyly of the presumed monophyletic family Hirudinidae was tested with the Templeton test [40] as implemented in PAUP* [4.02b]. Bayes Factors were calculated using the equation $2[\ln$ (harmonic mean of constraint) - $\ln$ (harmonic mean of original analysis)] in which strongly negative values (below -10) indicate rejection of the constrained analysis [41]. In addition, topological tests were conducted under the likelihood criterion with Treefinder [19] in which independent (unlinked) models were employed for the locus and codon partitions defined as above. Constraints that were compared to the optimal solution included 1) all traditional Hirudinidae 
taxa as monophyletic but excluding the non-bloodfeeding haemopids, and 2) all traditional Hirudinidae taxa and traditional Haemopidae taxa as monophyletic but not constraining either of these two subgroups to individually be monophyletic.

\section{Authors' contributions}

AJP and MES contributed equally to each stage of project conception and design, data collection, phylogenetic analyses, and preparation of the manuscript. Both authors have read and approved the final manuscript.

\section{Acknowledgements}

We thank M. Teresa Aguado, Sebastian Kvist, Frank Fontanella, Sara Watson, and Jessica E. Light for their comments on drafts of this paper. Special thanks goes to Elizabeth Borda and Alejandro Oceguera-Figueroa, for without their moral support and work on terrestrial leeches and the leeches of Mexico, respectively, much of this study would not have been possible. We thank Dr. Wayne Van Devender for his contributions in field work, providing specimens, and also for the guidance he provided AJP. For providing specimens, we thank Dr. Lorenzo Prendini, Dr. Gene Burreson, Dr. Olrec Kutschera, and Dr. Will Reeves. This work was financially supported by the National Science Foundation (DEB-0640463), the Stavros Niarchos fund for Expeditionary Research, a CUNY Science Fellowship, the Appalachian Center for Undergraduate Research fund, and the Heltzer Honors Program of Appalachian State University.

\section{References}

I. Sternback GL, Varon J, Fromm RE Jr, Sicuro M, Baskett PJF: Galen and the origins of artificial ventilation, the arteries and the pulse. Resuscitation 2001, 49: I 19-122.

2. Schwartz S: Psychoactive Herbs in Veterinary Behavior Medicine Oxford: Blackwell Publishing; 2005.

3. Porter R: The greatest benefit to mankind: a medical history of humanity New York: W. W. Norton \& Company;; 1999.

4. Gross MP, Apesos J: The use of leeches for treatment of venous congestion of the nipple following breast surgery. Aesthetic Plast Surg 1992, 1 6:343-348.

5. Morabia A: P.C.A. Louis and the Birth of Clinical Epidemiology. J Clin Epidemiol 1996, 49:1327-1333.

6. Wells S, Combes W: The Status and Trade in the Medicinal Leech. Traffic Bulletin 1987, 8:64-69.

7. Derganc $M$, Zdravic F: Venous congestion of flaps treated by application of leeches. Br J Plast Surg 1960, I3:187-192.

8. Rados C: Beyond Bloodletting: FDA gives leeches a medical makeover. FDA Consumer Magazine 2004 [http://www.fda.gov/].

9. Pirkle H, Markland FS: Hemostasis and animal venoms: symposium on animal venoms and haemostasis; 1985 San Diego, California. Boca Raton: CRC Press; 1988.

10. Haas G: Versuche der blutauswaschung am lebenden mit hilfe der dialyse. Klin Wochenschr 1924, 4:13-14.

II. Siddall ME, Trontelj P, Utevsky SY, Nkamany M, Macdonald KS III: Diverse molecular data demonstrate that commercially available medicinal leeches are not Hirudo medicinalis. Proc Roy Soc London B 2007, 274: |48 | - 487.

12. Kutschera U: The infamous blood suckers from Lacus Verbanus. Lauterbornia 2006, 56: I-4.

13. Hong SJ, Sawyer RT, Kang KW: Prolonged bleeding from the bite of the Asian medicinal leech Hirudo nipponia. Comp Haem Int 1999, 9:|25-|3|.

14. Richardson RL: A contribution to the systematics of the hirudinids leeches, with description of new families, genera and species. Acta Zool Acad Sci Hung 1969, I5:97-I49.

15. Sawyer RT: Leech Biology and Behaviour Oxford: Clarendon Press; 1986.

16. Apakupakul K, Siddall ME, Burreson EM: Higher-level relationships of leeches (Annelida: Clitellata: Euhirudinea) based on morphology and gene sequences. Mol Phylogenet Evol 1999 , I 2:350-359.

17. Borda E, Siddall ME: Arhynchobdellida (Annelida: Oligochaeta: Hirudinidae): Phylogenetic relationships and evolution. Mol Phylogenet Evol 2004, 30:2 I 3-225.

18. Soós Á: Identification key to the leech (Hirudinoidea) genera of the world, with a catalogue of species. I. Families: Semiscolecidae, Trematobdellidae, Americobdellidae, Diestecostomatidae. Acta Zool Acad Sci Hung 1969, I 2: | 45-160.

19. Jobb G: TREEFINDER version of October, 2008. 2008 [http:// www.treefinder.de]. Munich, Germany

20. Baskova IP, Zavalova LL: Proteinase inhibitors from the medicinal leech Hirudo medicinalis. Biochemistry Moscow 200I, 66:703-717.

21. Salzet M: Leech thrombin inhibitors. Curr Pharmaceut Des 2002, 8:493-503.

22. Munro R, Siddall ME, Desser SS, Sawyer RT: Bleeding in human volunteers from the bite of the American medicinal leech Macrobdella decora compared with its European counterpart Hirudo medicinalis. Comp Haematol Int 1991, I:2 |4-2 I6.

23. Munro R, Siddall ME, Desser SS, Sawyer RT: The leech as a tool for studying comparative haematology. Comp Haematol Int 1992, 2:75-78.

24. Richardson RL: On the zoological nature of land-leeches in the Seychelles Islands, and a consequential revision of the status of land-leeches in Madagascar (Hirudinea: Haemadipsoidea). Rev Zool Afr 1978, 92:837-866.

25. Moore JP: Notes on some Asiatic leeches (Hirudines) principally from China, Kashmir and British India. Proc Acad Nat Sci Phila 1924, 76:343-388.

26. Siddall ME, Budinoff RB, Borda E: Phylogenetic evaluation of systematics and biogeography of the leech family Glossphoniidae. Invert Syst 2005, 19:105-I 12.

27. Baraboshkin EY, Alekseev AS, Kopaevich LF: Cretaceous palaeogreography of the North-Eastern Peri-Tethys. Palaeogeogr Palaeoclimatol Palaeoecol 2003, I 96: I77-208.

28. Sawyer RT, Hechtel FOP, Hagy JW, Scacheri E: A study in medical history: introduction of medicinal leeches into the West Indies in the nineteenth century. Zoosystema 1998, 36: 1269-1289.

29. Kutschera $U$, Roth $M$ : Notes on the ecology of the Asian medicinal leech Hirudinaria manillensis (Hirudinea: Hirudinidae). Lauterbornia 2006, 56:9-13.

30. Sciacchitano I: Sanguisughe del Congo Belga. Revue Zool Bot afr 1935, 26:448-460.

31. Sciacchitano I: Nuovi Irudinei del Congo Begla. Revue Zool Bot afr 1939, 32:348-367.

32. Sciacchitano I: Irudinei del Congo Belga. Ann Mus $r$ Congo belge Sér 8vo (Sci zool) 1952, 16: I-87.

33. Bely AE, Wray GA: Molecular phylogeny of naidid worms (Annelida: Clitellata) based on cytochrome oxidase I. Mol Phylogenet Evol 2004, 30:50-63.

34. Edgar RC: MUSCLE: a multiple sequence alignment method with reduced time and space complexity. BMC Bioinformatics 2004, 5: II3.

35. Swofford D: PAUP*4.02b: Phylogenetic Analysis Using Parsimony (*and other methods). Version 4.0b Computer software and manual Sunderland: Sinauer Associates; 2002.

36. Farris JS, Albert VA, Källersjö M, Lipscomb DL, Kluge AG: Parsimony jackknifing outperforms neighbor-joining. Cladistics 1996, I 2:99-124.

37. Ronquist F, Huelsenbeck JP: MRBAYES 3: Bayesian phylogenetic inference under mixed models. Bioinformatics 19: I572-1574.

38. Posada D, Crandall KA: Modeltest: testing the model of DNA substitution. Bioinformatics 1998, I4:817-818.

39. Posada D, Buckley TR: Model selection and model averaging in phylogenetics: advantages of Akaike Information Criterion and Bayesian approaches over likelihood ratio tests. Syst Biol 2004, 53:793-808.

40. Templeton AR: Phylogenetic inference from restriction endonuclease cleavage site maps with particular reference to the evolution of humans and the apes. Evolution 1983, 37:22 |-244.

41. Brown JM, Lemmon AR: The importance of data partitioning and the utility of bayes factors in Bayesian phylogenetics. Syst Biol 2007, 56:643-655. 